\title{
Dar cara: de miradas, cuerpos y pedagogía en tiempos de confinamiento ${ }^{1}$
}

\author{
Damaso Andrés Rabanal Gatica \\ Universidad Austral de Chile²
}

\author{
Me gustan los estudiantes porque son la levadura \\ del pan que saldrá del horno con toda su sabrosura, \\ para la boca del pobre, que come con amargura. \\ Caramba y zamba la cosa, \\ ¡viva la literatura! \\ Violeta Parra, 1965
}

"Dar cara", esa fue la expresión que algunxs de mis estudiantes expresaron al inicio de este año académico, cuando las emergentes versiones de la peste tiraban los tentáculos por el mundo y nos confinamos — quienes pudimos- en una cuarentena autoimpuesta, con luces de neón que decían \#QuédateEnCasa. Curiosa expresión, pensé, considerando que la mayoría de las personas precisamente no puede hacerlo y han tenido que convocar al ingenio para escribir sus propias notas de inmunización imaginada.

"Dar cara", en hecho y en consigna, opera como la proyección articulada de entusiasmo y resignación. Una inflexión curiosa y creativa, que construye una base emocional para explicarse — en parte — la situación de pandemia y la vida universitaria enmarcada en pantallas, que transitan entre computadores, tablet y celulares.

"Dar cara" es la expresión que, en este momento de "covicho" — como dice una amiga-, hace traslúcidos los cuerpos, móviles, virtuales y los pone en una lámina iluminada que muestra otros contextos. En estos tiempos de necesaria y permanente movilización política, por ejemplo, 'poner el cuerpo' es 'dar cara'.

1 Las reflexiones presentadas enmarcan al proyecto FiloCyT "Régimen escópico, lenguaje, cuerpo y política en la literatura y las artes latinoamericanas contemporáneas" (FC 19-002) perteneciente al Instituto de Filología Hispánica "Dr. Amado Alonso", Facultad de Filosofía y Letras, Universidad de Buenos Aires.

2 Profesor del instituto de Ciencias de la Educación, Facultad de Filosofía y Humanidades. UACh. e-mail: damaso.rabanal@uach.cl ; ORCID No: 0000-0003-2484-0867 
Extrañamos la presencialidad, pero tenemos una memoria de la presencia — un susurro de Didi-Huberman (2017) se escucha en el ambiente-. Incluso velorios virtuales, donde la situación es todavía más particular, porque no solamente el cuerpo está virtualizado, si no que la materialidad de la presencia habita un ataúd, mientras, quienes participamos, invocamos una memoria que reconstruye emocionalmente a quien no podemos ver.

Esta situación nos ha impulsado a posicionar nuestras prácticas emocionales físicas a prueba: no podemos abrazar, sin embargo hemos aprendido a leer los rostros en pantalla y aprender el lenguaje de los ojos en la calle, cuando las mascarillas solo nos dejan ver esa franja de rostro. Incluso más allá, al poner a prueba la cordialidad, más de una vez saludamos a quienes creemos conocer, pero esa presencialidad anhelada nos ha vuelto más sensibles, o al menos más conscientes de cómo se distribuye y distribuimos nuestra sensibilidad (Ranciére 2014), porque al saludo distante la respuesta es inmediata... Y luego, la carcajada enmascarada, en el caso de construir una identidad que deseamos presente, pero que no era.

Inicialmente, porque la vida transita como las identidades, las diferentes pantallas parecieron nichos de cementerio — al parecer la influencia funeraria de tiempos de pandemia están permeando demasiado, aunque "nada más seguro que la muerte”, decía mi Abuelita María-. Negros y con letra blanca, como lápidas invertidas, que decían los nombres de estudiantes. Lo sé, una imagen tétrica que se terminaba de completar con voces cortadas por las diferentes capacidades de conexión a internet o al silencio sepulcral de personas que no hablaban. Una pausa y observar: estábamos acercándonos a nuevas interacciones forzadas por el contexto, más o menos exitosas, en medio de múltiples deseos y horizontes posibles. Salí de mi visita al panteón cuando comenzaron a sacar provecho al chat y el nuevo desafío fue armar las tramas de sentido de esas contribuciones. Se vuelve a diversificar la mirada y la comunicación, ahora las palabras dan cuerpo y presencia a Valeria, Camila, Andrés, Daniela, Bárbara, Darío, Gustavo, Ana, Francisco, Valentina y muchxs otrxs.

El siguiente tránsito fue cambiar los nombres de letra blanca por fotografías, algunas más profesionales y otras más motivacionales.

Pedagógicamente, si es que es posible pensarlo de esta manera, el confinamiento y la vida virtual nos ubica en un lugar de inflexión, una bisagra entre el contexto personal y el colectivo. Evidentemente, es cierto que no he conocido presencialmente a mis estudiantes y ellxs tampoco a mí, sin embargo, las clases virtuales me han permitido experimentar un giro al confinamiento.

Desde mi cuarentena autoconvocada, las clases han tenido diferentes visitas y se han ampliado los alcances posibles una sesión convencional. He conocido ma- 
dres, hermanxs, abuelitxs, hijxs, mascotas, pololxs (novixs) y, si me permito volver al cruce con la sensibilidad, he podido conocer los espacios que habitan mis estudiantes, las condiciones materiales en las que estudian, las dificultades logísticas de lo que significa tratar de estudiar desde casa, en el entendido que las familias —en su amplitud de posibilidades — no necesariamente comprenden lo que significa llevar adelante un proceso de aprendizaje que, además, está transformado en virtual por fuerza del contexto.

Les agradezco enormemente a mis estudiantes por abrir sus cámaras, porque es abrir una ventana a sus diseños familiares y desafíos personales. 'Dar cara' como gesto político de empuje, 'dar cara' con orgullo, 'dar cara' haciendo circular sus experiencias de vida, permeando los aprendizajes de la trayectoria educativa universitaria para avanzar en su proceso de formación inicial docente.

La mayor interferencia al confinamiento la vivimos el 25 de octubre de 2020, donde más del 80\% de lxs votantes decidimos poner el cuerpo y la esperanza en las calles y las urnas de votación. En un día mágico, decidimos 'dar cara' en el plebiscito que permitirá diseñar una nueva constitución. Es noche, cuarentena y constitución se sintetizaron en cuadro social de euforia y felicidad que pareció suspender la pandemia. Capucha y mascarilla en una misma algarabía deseosa de dignidad, formaban danzas nacionales donde las pistas de baile fueron las plazas de las ciudades. Esos mismos lugares, donde la impunidad tiñe el suelo con sangre, son la escena de una fraternización amorosa donde todxs podemos tejer un horizonte diferente para nuestras vidas y sueños.

El lunes 26 de octubre, en cambio, fue distinto 'dar cara'. Luego de un año de movilizaciones, y sobrevivir a las diferentes acciones y tecnologías de la violencia, circulan otras fuerzas.

Desde que 'damos cara' en las clases virtuales, suelo comenzar las sesiones con alguna canción representativa de lo que conversaremos y aprenderemos en esa sesión —igracias por tanto, a la música y al canto!- Por supuesto que esa semana inició con Violeta Parra y 'Me gustan los estudiantes', Sol y lluvia con 'Adiós General' (1980) o 'Sembrando esperanza' (1988), mientras mi amiga María José decía "La mía es 'Canción para mañana' de Los Bunkers (2003)" y yo recordaba sus poderosas lecturas y análisis desde las creaciones musicales recientes de Anita Tijoux — ‘Cacerolazo' (2019) — o Daniela Millaleo. Fue desafiante proponer una canción a la primera clase, y fueron ellxs, como siempre lxs estudiantes, quienes propusieron su música para alentarnos a nosotrxs.

Todavía nos queda confinamiento, un estallido social activo, las proyecciones de la pandemia son inciertas, así como las posibilidades de vacunación y tenemos un enorme desafío político constitucional próximamente: ¿Cuál es el soundtrack con 
Dar cara: de miradas, cuerpos y pedagogía en tiempos de confinamiento

Dámaso Rabanal

que 'daremos cara' al escribir la nueva constitución? ¿Qué cantaremos con nuestros estudiantes cuando dejemos de 'dar cara' y volvamos a poner el cuerpo?... ¿Y tú? ¿Cuál es tu canción para compartir y ‘dar cara’ frente a nuevos horizontes?

"Mañana habrá promesas en mi puerta para abrir"

(Los Bunkers, 2003) 


\section{Obras citadas}

Didi-Huberman, Georges. Lo que vemos, lo que nos mira. Buenos Aires: Manantial. 2017.

Los Bunkers. “Canción para mañana”. En La culpa [CD]. 2003. En línea: https:// www.youtube.com/watch? $\mathrm{v}=\mathrm{naOgZYaNRn8}$

Parra, Violeta. "Me gustan los estudiantes". En Cauce. 1965.

Ranciére, Jacques. El reparto de lo sensible. Buenos aires: Prometeo. 2014.

Sol y lluvia. "Adiós general". En Canto+vida [CD]. 1980. En línea: https://www. youtube.com/watch?v=MTcLoQp6bnM

Sol y lluvia. "Sembrando esperanzas". En Mas personas [CD]. 1988. En línea: https:// www.youtube.com/watch? $\mathrm{v}=4 \mathrm{sOlagA66 \textrm {KQ }}$

Tijoux, Ana. “Cacerolazo”. 2019. En línea: https://www.youtube.com/ watch? $=\mathrm{tVaTuVNN7Zs}$ 